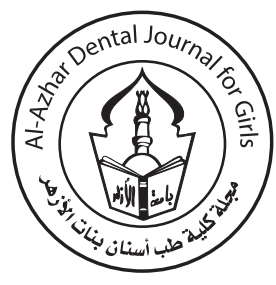

\title{
Effect of Application of Natural versus Synthetic Desensitizing Agents on Dentin Permeability
}

\author{
Menna-Allah S. Ali ${ }^{1 *}$, Maha A. Niazy ${ }^{2}$, Mohamed A. El-Yassaky ${ }^{3}$.
}

Codex : 02/21.07

azhardentj@azhar.edu.eg

http://adjg.journals.ekb.eg

DOI: $10.21608 /$ adjg.2021.23242.1230

Restorative Dentistry

(Removable Prosthodontics, Fixed

Prosthodontics, Endodontics, Dental Biomaterials, Operative Dentistry)

\section{KEYWORDS}

Bio active glass, Pro-Argin, Moringa extract, permeability, Dye penetration.

\begin{abstract}
Purpose: This in vitro study was established to compare the effect of natural versus synthetic desensitizing agents on dentin permeability. Materials and Methods: Class V cavity preparation was done on the labial surface of 40 premolars for cervical dentin assessment, while for coronal dentin; class I cavity was prepared on the occlusal of 40 premolars. Cavities were etched with phosphoric acid then classified according to treatment either by Bio active glass, Pro-Argin, Moringa extract or untreated (control). The dentin permeability was done using dye penetration test with Evans blue dye. The depth of dye penetration in dentin was examined using stereomicroscope. Results: The results showed that the lowest statistically significant mean depth of dye penetration values were found with Bio active glass followed by Pro-Argin, then Moringa extract. Conclusion: Among the three treatment modalities, Bio active glass and Pro-Argin can be considered as effective materials in the management of hypersensitivity.
\end{abstract}

\section{INTRODUCTION}

Dentin hypersensitivity is described as a clinical condition in which sharp pain arises after exposure of bare dentin to mechanical, chemical or thermal stimuli ${ }^{(1)}$. Hypersensitive teeth have wider and more patent dentinal tubules than those in non-sensitive teeth. The movement of dentinal fluid inside these wide dentinal tubules indirectly stimulates the nerve endings leading to pain sensation. Dentin hypersensitivity pain could be controlled if these dentinal tubules become completely or partially occluded ${ }^{(2)}$.

- Paper extracted from PHD Thesis titled "Effect of Application of Natural Versus Synthetic Desensitizing Agents on Dentin Permeability"

1. Assistant lecturer of Operative Dentistry, Faculty of Dental Medicine for Girls, Al-Azhar University, Cairo, Egypt

2. Professor of Operative Dentistry, Faculty of Dental Medicine for Girls, Al-Azhar University, Cairo, Egypt.

3. Professor of Operative Dentistry \& Dean of Faculty of Dentistry, Sinai University, Egypt.

* Corresponding author email: msa789@ hotmail.com 
Bioactive glasses (BGs) are highly biocompatible materials; their active ingredient is calcium sodium phosphosilicate ${ }^{(3)}$. Dissolution of $B G$ in physiological liquid environments induces the formation of calcium phosphate precipitates which are effective in hard tissue regeneration and remineralization $^{(4)}$.

Pro-Argin system is based on the natural process of occlusion of dentinal tubules. The proargin system is composed of a positively charged amino acid at physiological $\mathrm{pH}$ (arginine), a source of calcium (calcium carbonate) and bicarbonate as $\mathrm{pH}$ buffer ${ }^{(5)}$. The mechanism of action of pro-Argin is described as there is an interaction between calcium carbonate and arginine leading to the formation of layer rich in calcium which binds to the dentin leading to occlusion of dentinal tubules ${ }^{(6)}$.

Moringa oleifera has a wide range of medicinal uses and high nutritional value throughout the world. The leaves and stems have a large amount of calcium, vitamins, iron, vitamin $\mathrm{c}$ and potassium ${ }^{(7)}$.

\section{MATERIALS AND METHODS}

Three treatment modalities were used: Bio active glass, Pro-Argin, and Moringa extract.

\section{1- Teeth selection:}

Eighty human premolars extracted for orthodontic reasons (age range 20-40) were included. Collection of the teeth was done after informing the donors about the use of their teeth according to the protocol permitted by the ethical committee of Faculty of Dentistry, Al-Azhar University. Teeth were washed with water to remove blood and scraped with scaler to remove attached periodontal tissue, plaque and calculus, then stored in distilled water and used within one month.

Inclusive criteria: Non carious teeth free from decay, cracks or defects on the surface.

Exclusive criteria: teeth with surface defects, decay, cracks, or restoration, were discarded.

\section{2- Teeth grouping:}

Teeth were allocated into four main groups of (20) each, regarding to the treatment agent applied:

$\mathbf{A}_{1}$ : Samples were left without treatment (Control).

$\mathbf{A}_{2}$ : samples were treated with bioactive glass.

$\mathbf{A}_{3}$ : samples were treated with pro-Argin.

$\mathbf{A}_{4}$ : samples were treated with Moringa extract.

Each group included two subgroups of (10) samples regarding to dentin location:

$\mathbf{B}_{1}$ : Coronal dentin.

$\mathbf{B}_{2}$ : Cervical dentin

\section{3- Teeth preparation:}

\section{a- Class I cavities:}

Cavities were done on the occlusal surface of the selected teeth. The width of the cavity was about one-fourth of intercuspal distance and the depth was about $0.5-1 \mathrm{~mm}$ under the dentino-enamel junction (DEJ). All the cavities were treated with $37 \%$ phosphoric acid gel for 30 seconds, rinsed for $30 \mathrm{sec}$. In order to simulate the clinical condition of dentin hypersensitivity, acid was reapplied for $3 \mathrm{~min}$ to open the dentinal tubules.

\section{b-Class V cavities}

Cavities were done on both buccal and lingual surfaces of the selected teeth. Cavities depth was $0.8 \mathrm{~mm}$ depth and width was $2 \mathrm{~mm}$. Cavities were prepared on the cervical region $1 \mathrm{~mm}$ coronal to the cervical line using round burs \#6 carbide bur on low-speed hand piece under water coolant ${ }^{(8)}$. An endodontic file stopper was placed at the termination of the bur head to control the depth. The bur was replaced every 10 preparations. Each tooth was then sectioned longitudinally, in mesiodistal direction, into two parts (buccal and lingual) using double faced diamond disc. Then each tooth part was embedded in heavy body rubber base blocks 
to allow for easy handling of the sample during the application procedures and removal after the dye application procedure. Phosphoric acid was applied as mentioned previously.

\section{4- Application of treatment agents: (Fig. 1)}

\section{A. Application of Bioactive glass:}

The material was applied to the cavity using a plastic syringe, the paste was brushed using a micro brush for $20 \mathrm{sec}$ and left in the cavity for $2 \mathrm{~min}$.

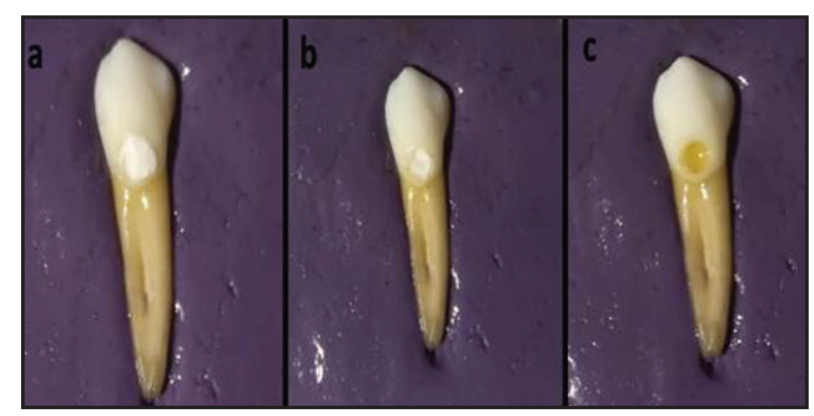

Figure (1): Application of the materials. a: Bioactive glass, b: Pro-Argin, c: Moringa extract

\section{B. Application of Pro-Argin:}

The freshly evacuated pro-Argin paste was applied to the prepared cavities and dentin surfaces using micro brush and left for $2 \mathrm{~min}$ and then removed using cotton pellets.

\section{Application of Moringa:}

Moringa extract was applied into the cavities using microbrush and left for $2 \mathrm{~min}$. Removal of the material was done using cotton pellets.

After application of the tested materials, samples were placed in artificial saliva solution and incubated in a laboratory incubator at $37^{\circ} \mathrm{C}$ for 24 hours. After incubation, the samples were washed using distilled water for $30 \mathrm{sec}$ and dried with air from dental unit triple syringe for additional 30 seconds.

\section{5- Assessment of Dentin permeability:}

5\% Evans blue dye solution was applied to the cavities using plastic syringe and left for $20 \mathrm{~min}$, then rinsed and air dried. Cervical dentin samples were sectioned longitudinally (bucco-lingual direction) through the center of the cavities using double faced diamond disc in cutting machine. Only one half of each sample was examined. While Coronal dentin samples were sectioned mesio- distally.

\section{6- Stereomicroscope evaluation:}

The samples were examined using Stereomicroscope. Capturing the image was done at40 $\times$ magnification and 5.1 megapixels using (digital camera, Olympus Camedia C- 5060 Tokyo, Japan). Dentin permeability was assessed by measuring the depth of the dye infiltration for each specimen using an image analysis program: image J (National Institute of Health, USA). Each image was evaluated individually. All of the measurements were performed by the same examiner ${ }^{(9)}$.

\section{RESULTS}

Data were explored for normality using Kolmogorov-Smirnov test of normality. One way ANOVA was used for testing significance of the treatment agent on dye penetration depth. The significance level (P-value) was set at $\mathrm{P} \leq 0.05$, while $\mathrm{p} \leq 0.01$ and 0.001 indicated highly significant. Data were analyzed by computer with statistical program SPSS version 19.0 (Statistical Package for Scientific Studies, IBM Corp., USA).

The lowest statistically significant mean values depth of dye penetration were found using bio active glass, recording $(54.45 \pm 15.2)$, followed by Pro-Argin recording $(84.87 \pm 13.96)$, then Moringa extract treated group, recording $(171 \pm 3.8)$ There was statistical significant difference between the three treatment modalities. Table (1) and figure (2). 
Table (1): Comparison of the mean dye penetration depth between the three treatment modalities

\begin{tabular}{|c|c|c|c|c|c|c|c|c|c|}
\hline \multirow{2}{*}{$\begin{array}{l}\text { Dentin } \\
\text { Location }\end{array}$} & \multicolumn{2}{|c|}{$\begin{array}{c}\text { Control } \\
\left(\mathrm{A}_{1}\right)\end{array}$} & \multicolumn{2}{|c|}{$\begin{array}{c}\text { Bio active Glass } \\
\left(\mathrm{A}_{2}\right)\end{array}$} & \multicolumn{2}{|c|}{$\begin{array}{c}\text { Pro-Argin } \\
\left(\mathrm{A}_{3}\right)\end{array}$} & \multicolumn{2}{|c|}{$\begin{array}{c}\text { Moringa extract } \\
\left(\mathrm{A}_{4}\right) \\
\end{array}$} & \multirow{2}{*}{ P-Value } \\
\hline & Mean & SD & Mean & SD & Mean & SD & Mean & SD & \\
\hline Coronal dentin $\left(B_{1}\right)$ & $394.21^{\mathrm{a}}$ & 64.93 & $51.88^{\mathrm{c}}$ & 13.43 & $92.18^{\mathrm{b}}$ & 31.11 & $181.87^{\mathrm{a}}$ & 18.69 & \multirow{2}{*}{$\begin{array}{l}0.000 \\
\text { (HS) }\end{array}$} \\
\hline Cervical dentin $\left(B_{2}\right)$ & $305.03^{b}$ & 78.94 & $54.45^{\mathrm{c}}$ & 15.20 & $84.87^{\mathrm{b}}$ & 13.96 & $171.38^{\mathrm{a}}$ & 38.11 & \\
\hline
\end{tabular}

Tukey's post hoc test: means with different superscript letters are significantly different.

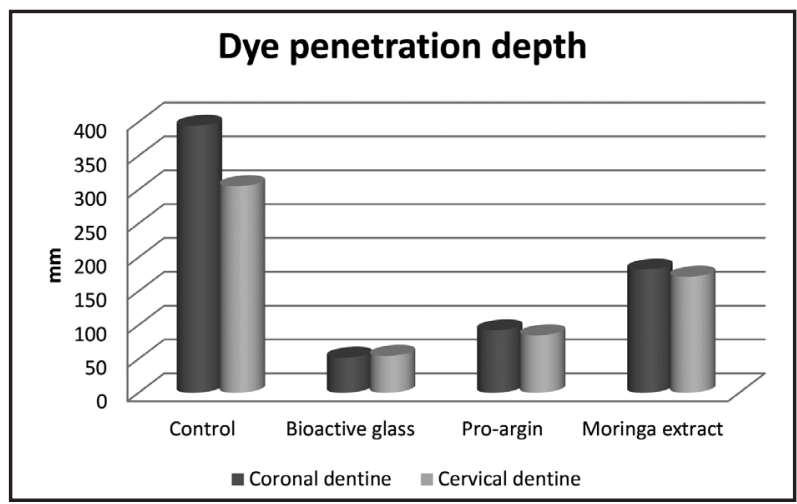

Figure (2): Bar chart illustrating dye penetration depth of different variables interactions.

\section{DISCUSSION}

Human premolars were involved in the in vivo study as it was reported that the most affected teeth of both arches are canines and premolars ${ }^{(10)}$. Cavities were prepared to be wide and with small depth for easy application of the materials and to ensure that these materials are with intimate contact with the dentin. Evans blue dye has been used in previous studies for assessment of dentin permeability. Diffusion of dye into dentinal tubules is a reliable technique for determining the effectiveness of desensitizing agents in reducing dentin permeability ${ }^{(9)}$.

In the current study regarding to depth of dye penetration; the Bio active group recorded significantly lower dentin permeability (lower dye penetration depth) than the control group in both coronal and cervical dentin. This effect of Bio active glass may be referred as it forms a hydroxycarbonate ap- atite (HCA) layer on the surfaces of the particles, and also to its ability to occlude dentinal tubules mechanically ${ }^{(11)}$. The presence of HCA layers over BG particles surfaces allow them to bind to each other and to the walls of dentinal tubule, which enhance their effect on the occlusion of dentinal tubules ${ }^{(12)}$. The result obtained was in accordance to a previous study proposed that the occlusion effects of bioglass were excellent after brushing using toothpaste containing it and after artificial saliva immersion ${ }^{(13)}$.

The Pro-Argin group recorded significantly lower dentin permeability (lower dye penetration depth) than the control group in both coronal and cervical dentin. This could be attributed to the formation of positively charged agglomerate; by the adsorption of the arginine onto the calcium carbonate surface, which binds to the dentin on the exposed surfaces and inside the dentinal tubules ${ }^{(14)}$. Moreover, the arginine-calcium carbonate agglomerate has an alkaline $\mathrm{pH}$ which enables the precipitation of calcium and phosphate from dentin fluid and saliva ${ }^{(15)}$. This was in accordance with an in vitro study which has concluded that using toothpaste containing pro-Argin resulted in occlusion of open dentinal tubules (16). Contrarily, a previous study reported that the Pro-Argin group revealed no significant difference before and following treatment. This may be explained due to difference in the material application and assessment methodology ${ }^{(17)}$.

Furthermore; the Moringa extract group recorded significantly lower dentin permeability (lower dye penetration depth) than the control group in 
both coronal and cervical dentin. This effect could be attributed to the presence of various nutrients in it such as calcium, phosphorus and others that are associated with dentinal tubule occlusion ${ }^{(18)}$. This was in agreement with an in vitro study which examined the effect of Moringa on enamel and dentin of both healthy and uremic patients. SEM showed that the diameter of dentinal tubules has been decreased in both groups ${ }^{(19)}$.

Moreover; on Comparing the effect of dentin location on dentin permeability reduction results presented that there was no statistically difference between all groups. This could be explained as since both groups are away from the pulp and located near to the DEJ this could suggest that they are nearly similar in the dentin permeability.

\section{CONCLUSION}

Within the limitation of the present study it could conclude that:

1. The use of Bio active glass, Pro-Argin and Moringa extract were effective in reducing dentin permeability.

2. Micromorphological changes of the dentin surfaces in terms of occluding the orifices of the dentinal tubules to variable degrees were evident.

\section{REFERENCES}

1. West N, Lussi A, Seong J, Hellwig E. Dentin hypersensitivity: pain mechanisms and aetiology of exposed cervical dentin. Clin Oral Invest. 2013;17:9-19.

2. Shiau HJ. Dentin hypersensitivity. J Evid Based Dent Pract. 2012; 12: 220-8.

3. Baino F, Hamzehlou S, Kargozar S. Bioactive Glasses: Where Are We and Where Are We Going? J. Funct Biomater. 2018;8:9-25.

.4 Rahaman M, Day D, Bal B, Fu Q, Jung S, Bonewald L, et al. Bioactive glass in tissue engineering, Acta Biomater. 2011;7:2355-73.

5. Petrou I, Heu R, Stranick M, Lavender S, Zaidel L, Cummins D, et al. A Breakthrough therapy for dentin hypersensitivity: How dental products containing $8 \%$ arginine and calcium carbonate work to deliver effective relief of sensitive teeth. J Clin Dent. 2009;20:23-31.
6. Kulal R, Jayanti I., Sambashivaiah S, Bilchodmath S. An In-vitro Comparison of Nano Hydroxyapatite, Novamin and Proargin Desensitizing Toothpastes - A SEM Study. J. Clin Diag Res. 2016;10:51-4.

7. Farooq F, Rai M, Tiwari A, Khan A, Farooq S. Medicinal properties of Moringa oleifera: An overview of promising healer. J Med Plan Res. 2012;6:4368-74.

8. Pinto S, Silveira M, Pochapski M, Pilatt G, Santos F. Effect of desensitizing toothpastes on dentin. Braz oral res. 2012;26:410-7.

9. Pinto S, Pochapski M, Wambier D, Pilatti L, Santos F. In vitro and in vivo analyses of the effects of desensitizing agents on dentin permeability and dentinal tubule occlusion. J Oral Sci. 2010;52:23-32.

10. Miglani S, Aggarwal V, Ahuja B. Dentin hypersensitivity: Recent trends in management. J Conserv Dent. 2010; 13:218-24

11. Jones R. Review of bioactive glass: from Hench to hybrids, Acta Biomater. 2013;9:4457-86.

12. Lee $\mathrm{S}, \mathrm{K}$ won H, Kim B. Effect of dentinal tubule occlusion by dentifrice containing nano-carbonate apatite. J Oral Rehabil. 2008;35:847-53.

13. Wang Z, Sa Y, Sauro S, Chen H, Xing W, Ma X, Jiang T, Wang, et al. Effect of desensitizing toothpastes on dentinal tubule Occlusion-A dentine permeability measurement and SEM in vitro study. J Dent 2010;38:400-10.

14. Li R, Li Y, Chen J, Zhou Z, Morrison BM Jr, Panagakos FS. Efficacy of a desensitizing toothpaste containing arginine and calcium carbonate on dentin surface pore structure and dentin morphology. Am J Dent. 2012;25:210-4.

15. Stoleriu S, Pancu G, Ghiorghe A, Sincar D, Solomon S, Andrian S, et al. Evaluation of Dentinal Changes Following Application of Three Different Desensitizing Agents. 2017;68:1573-7.

16. Kulal R, Jayanti I, Sambashivaiah S \& Bilchodmath S. An In-vitro Comparison of Nano Hydroxyapatite, Novamin and Proargin Desensitizing Toothpastes. J Clin Diag Res.2016;10:51-4.

17. Yang J, Hu H, Lee S, Hsieh S, Huang P, Chen M, et al., In Vitro Evaluation of Dentin Tubule Occlusion for Novel Calcium Lactate Phosphate (CLP) Paste. Mat.2017;10,228.

18. Sujatha B, Patel P. Moringa Oleifera - Nature's Gold. Imperial J Interdis Res. 2017;3:1175-9.

19. Khalaf E., Nagib A., Amin L., Ibrahim F. Biological effects of topical application of Moringa Oleifera extract versus fluoride on uremic patients extracted teeth. Int. J. Adv. Res.2016; 4:1513-20. 